\title{
MYCOFLORA ASSOCIATED WITH PAANCH PHORON AND ITS MANAGEMENT BY COMMON SALT
}

\author{
Shamim Shamsi*, Tania Sultana and Pranami Chowdhury ${ }^{1}$ \\ Department of Botany, University of Dhaka, Dhaka-1000, Bangladesh
}

Key words: Mycoflora, Paanch Phoron, Management, Common salt

Presence of fungi in Paanch Phoron was investigated and presented in this paper. Total fungal species and frequency percentage of association of the fungi with the spices were recorded. In total 10 species of fungi belong to 4 genera of the class deuteromycetes and one genus of the class Zygomycetes were found to be associated. The isolated fungi were Alternaria alternata (Fr.) Keissler, Aspergillus flavus Link, A. fumigatus Fresenius, A. nidulanss G. Winter, A. niger van Tiegh., A. terreus Thom, Aspergillus sp., Cladosporium sp, Fusarium sp. and Rhizopus sp. Efficacy of common salt $(\mathrm{NaCl})$ at 5, 10 and $20 \%$ concentrations was evaluated against fungal species associated with paanch phoron in vitro. Radial colony growth of fungi associated with inocula prepared from the samples were completely inhibited by salt at $20 \%$ concentration used up to six weeks of observation.

The name paanch phoron literally means "five spices" in Maithili (Paanch Phorana), Assamese (Pas Phorôn), Bengali (Pãch Phoron) and Oriya (Panchu Phutana)). This uniquely Bengali (east Indian) spice mix is used to season many dishes. It is a blend of five (Paanch) spices and lends a lovely aroma when added to a dish. Typically, Paanch Phoran is a colourful blend of flavourful seeds: the green of fennel seed, black mustard and nigella seeds, golden fenugreek and buff-coloured cumin seeds. Generally the ingredients are added in equal proportions, though this can vary according to taste. In the tradition of Oriya and Bengali cuisine, Paanch Phoron is typically fried in cooking oil or ghee, which causes it to start popping immediately. This technique is called "Phoron" in Bengali, "Baghaar" (literally "tempering") in Oriya, and chaunk in Hindi. Other ingredients are added at this point.

As well as spices, Paanch Phoron is derived from seeds of five plants and are contaminated with fungi (Hashem and Alamri 1988). Although it is used in food in small amounts and they are recognized as important carriers of microbial contamination mainly because of the conditions in which they were grown, harvested and processed. Fungal infestation of the produce may occur when seeds are not properly dried or when stored in a highly humid environment. Even produces stored at low temperature are vulnerable to some fungi. The presence of fungi in Paanch Phoron with formation of noxious orders and other adverse effects including the increased risks for mycotoxin formation under favourable condition (Ath-Har et al. 1988). Lot of research has been

*Corresponding author: <prof.shamsi@gmail.com>. ${ }^{1}$ Directorate of Secondary and Higher Education, Dhaka, Bangladesh. 
done abroad about fungal contamination of spices but in Bangladesh very little research has been done in this regard (Aheen et al. 2011), Imandel and Adibnia (2000) and Stakvileviciene (2003). This study was undertaken to determine the occurrence of fungi associated with Paanch Phoron and their management with common salt .

Experimental materials include in this study was packed Paanch Phoron (Pran and Radhuni brand) and Paanch Phoron samples collected from open market of Farmgate, Mirpur, New Market and Rai Shaheb Bazar of Dhaka city. Thirty samples were examined for fungal infestation of these spices. Fungal organisms from the samples were isolated following "Tissue Planting" method on PDA (Potato Dextrose Agar medium). Isolated fungi were identified following Standard Literature (Burnett and Hunter 2000, Ellis 1976, Repper and Fernel 1965).

Efficacy of common salt $(\mathrm{NaCl})$ was evaluated against fungal species associated with Paanch Phoran in vitro. Sodium chloride solution at 5,10 , and $20 \%$ was prepared and poured into sterilized Petri plates with PDA medium and was allowed to solidify. Each Petri plate was centrally inoculated with Paanch Phoron inocula. Two seeds from individual spices were used as inocula. In control set, requisite amount of distilled water was added instead of salt solution in Petri plates containing PDA medium. Three replications were maintained for both treatment and control sets. The inoculated Petri plates were incubated at $25 \pm 1^{\circ} \mathrm{C}$. The radial growth of the colonies was measured after 5 days of incubation.

The percentage growth inhibition of each test pathogen was calculated by using the following formula:

$$
I=\frac{C-T}{C} \times 100
$$

where, $\mathrm{I}$ = per cent growth inhibition, $\mathrm{C}$ = growth in control and $\mathrm{T}$ = growth in treatment.

Table 1 shows the frequency percentage of fungi associated with Paanch Phoron. In total 10 species were isolated from Paanch Phoron. The isolated fungi were Alternaria alternata, Aspergillus flavus, A. fumigatus, A. nidulans, A. niger, A. terreus, Aspergillus sp., Cladosporium sp., Fusarium sp. and Rhizopus sp. (Figs 1 and 2).

Samples from Farmgate open market was highly contaminated. Nine fungal species were found to be associated with the samples. Frequency percentage of association of $A$. niger was higher (25). Lower frequency percentage of association was recorded (10) in A. alternata and Aspergillus spp. Five fungal species were isolated from Pran and Radhuni Brand Paanch Phoron. Six fungal species were associated with sample collected from New Market and Mirpur market. Five fungal species were isolated from Rai Saheb Bazar. Frequency percentage of association of A. fumigatus and Fusarium sp. was higher (25) and lower (10) in A. niger and Rhizopus sp. 

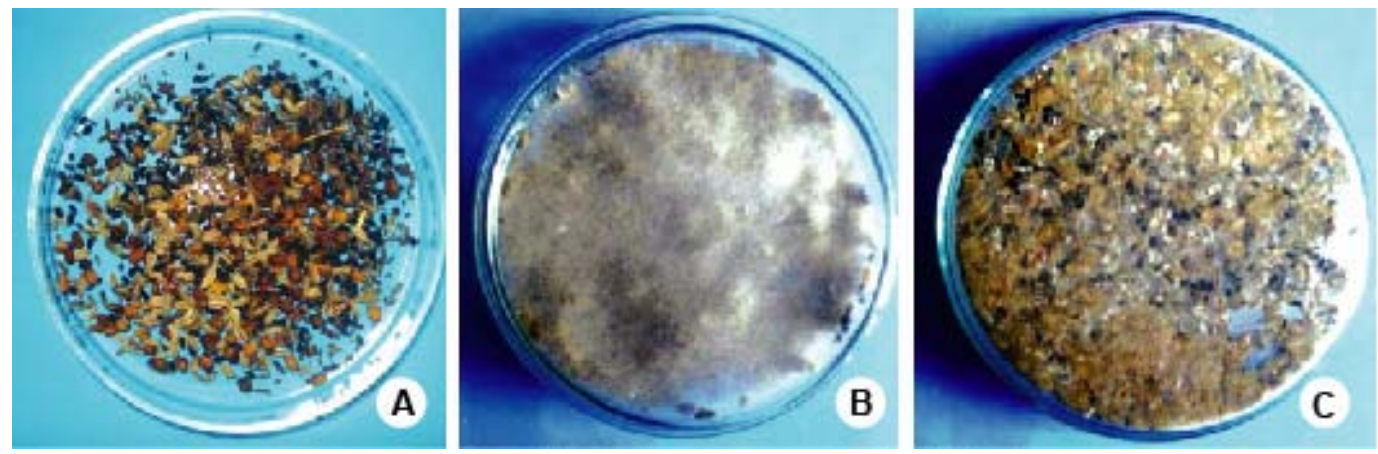

Fig. 1. Paanch Phoron: A. Healthy grains. B. Grains with fungal infestation (dorsal view). C. Ventral view.
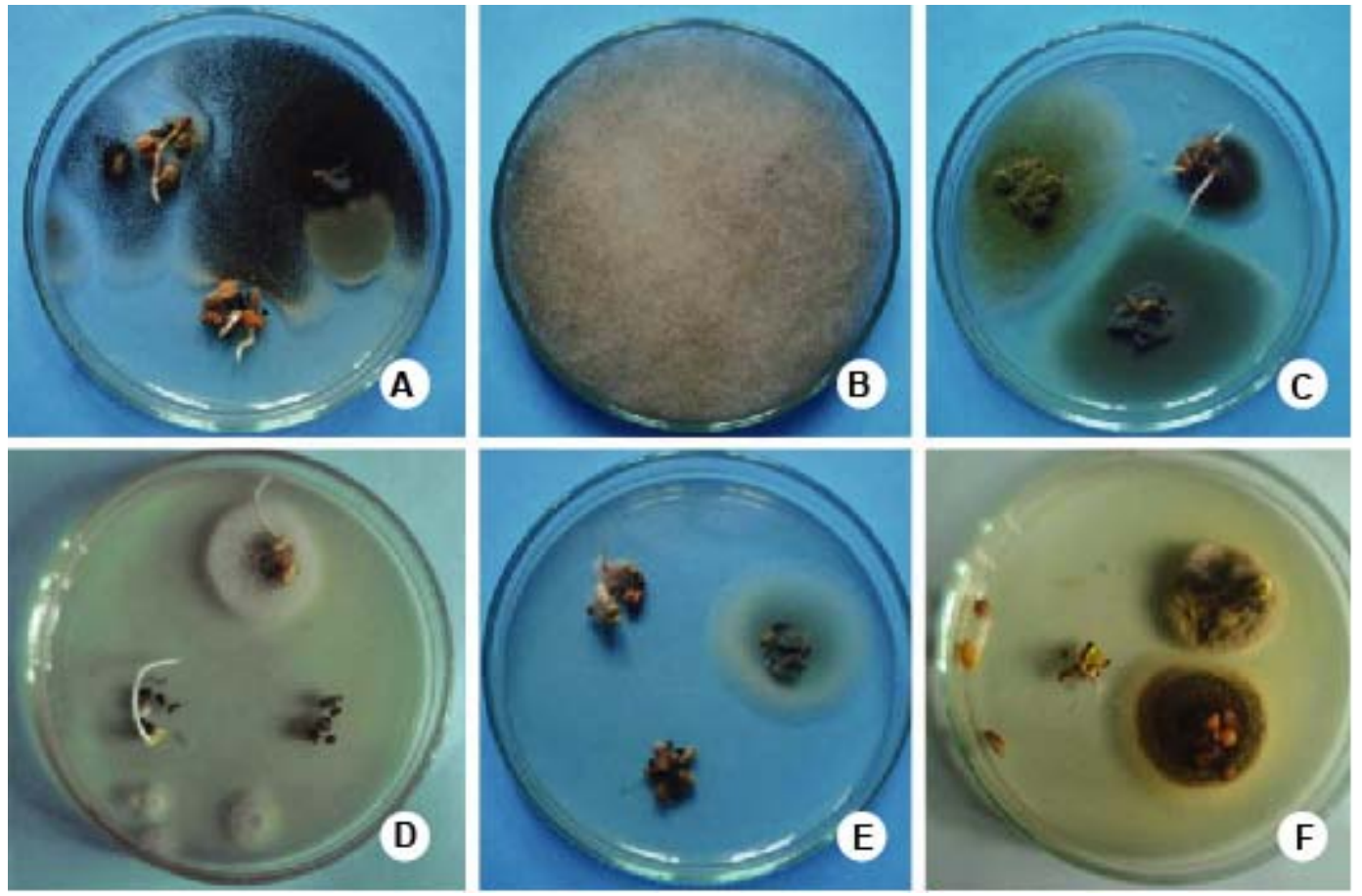

Fig. 2. Fungi associated with Paanch Phoron samples : A. Pran brand. B. Radhuni brand. C. Farmgate, D. Mirpur. E . New Market and F. Rai Saheb Bazaar.

Apart from imparting a unique flavour and taste, the five types of spices used in Paanch Phoron have significant health benefits too. The presence of cumin may stimulate the secretion of pancreatic enzymes, important factors in proper digestion and nutrient assimilation. As with other carminative spices, cumin's digestive stimulating effects are due to its content of volatile oils. Mustard is a good source of selenium and magnesium and is also a good source of omega-3 fatty acids as well as iron, calcium, zinc, manganese, magnesium, protein, niacin and dietary fiber. The 
seeds of the fenugreek plant are known to be great cleansers of the system and those of fennel acts as a digestive, appetite enhancer. Kalonji seeds have been known to have many healing properties including migraine, chronic colds, palpitations, alopecia, asthma (Wikipedia 2014).

Table. 1. Frequency percentage of association of fungi with Paanch Phoron.

\begin{tabular}{|c|c|c|c|c|c|c|}
\hline \multirow{2}{*}{ Fungi } & \multicolumn{2}{|c|}{ Brand } & \multicolumn{4}{|c|}{ Open market } \\
\hline & Pran & Radhuni & Farmgate & Mirpur & New Market & R S Bazar \\
\hline Alternaria alternata & - & - & 10 & - & - & - \\
\hline Aspergillus flavus & 10 & 10 & 10 & 20 & 10 & 22 \\
\hline A. fumigatus & 12 & 10 & 10 & 20 & 12 & 25 \\
\hline A. nidulans & - & - & 10 & - & - & - \\
\hline A. niger & 20 & 40 & 25 & 20 & 10 & 10 \\
\hline A. terreus & - & - & 10 & - & - & - \\
\hline Aspergillus sp. & - & - & 10 & - & - & - \\
\hline Cladosporium sp. & - & - & 10 & 20 & - & \\
\hline Fusarium sp. & 10 & 12 & 20 & 25 & 20 & 25 \\
\hline Rhizopus sp. & 25 & 30 & 20 & 10 & 10 & 10 \\
\hline
\end{tabular}

RS = Rai Saheb.

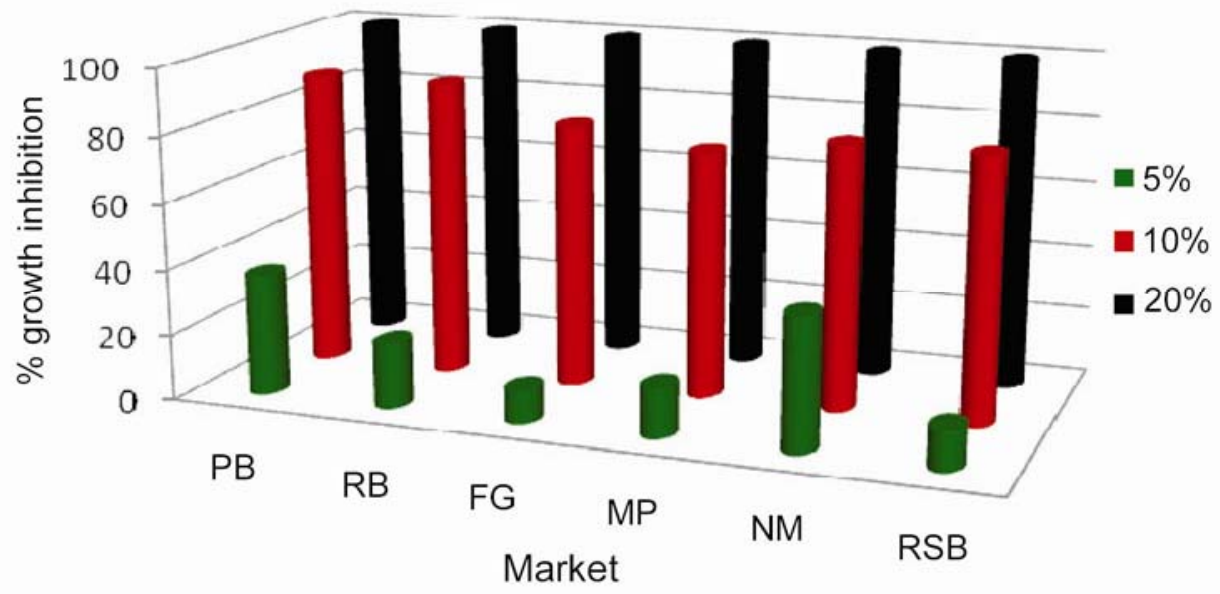

Fig. 3. Per cent inhibition of radial growth of the fungi associated with Paanch Phoron at different concentrations of sodium chloride. $(\mathrm{PB}=$ Pran Brand, $\mathrm{RB}=$ Radhuni Brand, FG $=$ Farmgate, $\mathrm{MP}=$ Mirpur, NM = New Market and RSB = Rai Saheb Bazar).

An ecofriendly management of these mixed spices is the demand of time to save it from fungal contaminant. All the samples were screened against sodium chloride at three concentrations. In this study sodium chloride at $20 \%$ has completely inhibited the radial growth of fungi associated with all the samples of Panch Phoran. At $10 \%$ concentration sodium chloride inhibited 90\% growth of fungi in samples of Pran and Radhuni brand. Samples of Farmgate, New 
Market and Rai Saheb Bazaar showed 80\% inhibition of the fungi followed by $75 \%$ inhibition of the fungi of the samples from Mirpur open market. At 5\% concentration highest inhibition of fungi was recorded $40 \%$ in the sample from New Market and lowest $10 \%$ inhibition of fungi was recorded in the samples from Farm gate open market (Fig. 3).

Antifungal activity of sodium chloride was reported by Esam (2009) on Saprolegnia diclina and Aphanomyces sp.

Present study indicates that Alternaria alternata, Aspergillus flavus, A. fumigatus, A. nidulans, A. terreus, Aspergillus sp. Cladosporium sp., Fusarium sp. and Rhizopus sp. associated with Paanch Phoran was completely inhibited by $20 \%$ of sodium chloride for a period of six weeks.

\section{References}

Aheen, R.E., G.T. Odamtten and E. Owusu. 2011. Fungal and bacterial contaminants of six spices products in Ghana. African Journal of Environmental Science and Technology. 5(9):633-640.

Ath-Har M.A., H.S. Prakash and H.S. Shetty 1988. Mycoflora of Indian spices with special reference to aflatoxin producing isolates of Aspergillus flavus. Indian J. Microbiol. 28:125-127.

Barnett, H. L. and B. B. Hunter. 1972. Illustrated Genera of Imperfect Fungi. Burgess Publishing Company, U .S. A. Third Edition. pp. 241.

Ellis, M.B. 1976. More Dematiaceous Hyphomycetes. Commonwealth Mycological institute, England. pp. 608.

Esam, H.A. 2009. Antifungal activity of sodium chloride on Saprolegnia diclina and Aphanomyced sp. Acta Mycologia 44(1):125-138.

Hashem, M. and S. Alamri. 2010. Contamination of common spices in Saudi Arabia markets with potential mycotoxin-producing fungi. Saudi J. Biol. Sci. 17(2):167-175.

Imandel, K. and H. Adibnia. 2000. Microbial contaminants of spices (termeric, black pepper and sumac) in western part of Tehran. Iranian Journal of Public Health 29((1-4): 37-44.

Rapper K.B. and D.I. Fennel 1965. The genus Aspergillus. The William and Wilkins Co., Krieger Pulb. Co. Huntigton, New York.

Stakvileviciene, S. 2003. Micro fungi on above ground parts of coriander (Coriandrum sativum L.). Vagas. 58: $39-42$.

Wikipedia, the free encyclopedia. 2014. Paanch Phoron.

(Manuscript received on 14 September, 2014; revised on 27 April, 2015) 